the fact of her having a fibrous tumour of the uterus, and sent her to the clinique of Dr. Apostoli on the 21st September. She was then unable to work, pale, emaciated, with lumbar and abdominal pains, made worse by any attempt to walk.

Neck and body of the uterus hypertrophied and hard, the front part being the principal seat of the fibrome. Measurement $8 \frac{1}{2}$ centimètres : cavity large. Intra-uterine positive galvano-cauterisation, 100 milliamperes, five minutes on the 23 rd September; repeated on the 28 th, 225 milliampères, five minutes; and on the $/$ th October, 250 milliampères, five minutes. No great pain, and she returned home an hour after each sitting. By the 11 th of January, 1887, ten cauterisations had been made. Natural menstruation began in September, and has since been regular, moderate, and without pain. The relief was so marked that she began her work of femme de ménage on the 21st of October. Treatment ceased in January, 1887, and she is at present (June) well, and working daily without inconvenience. She has gained in weight 16 lbs, and the measurement of the uterus is $7 \frac{1}{2}$ centimètres.

CASE II.-Madame P., aged 39, healthy, menstruated in early life regularly, abundantly, and painlessly. Five children between twentieth and twenty-ninth year. When 24 , had no appearance for six months Two months after her last confinement had a first attack of menorrhagia, great loss, lasting ten days, sharp and incessant pains. This returned when she was 36 , and went on for three years to the time of her consultation in October, 1885. Weight and pain in body, which render working and walking difficult. Health injured, and often obliged to remain in bed. Fibrous enlargement of uterus, especially of posterior part. Measurement, eight centimetres. From October 29 th, 1885 , to December, 1886, eighteen positive galvano-cauterisations, from 100 to 250 milliampères, for five minutes each. After the fifth sitting - there having been five intercurrent faradisations to allay the abnormal pains-improvement began. Pain lessened, movement became easy, and the organic functions were re-established. Menstruation appeared [regularly and in natural proportions after the tenth sitting, loss only during two or three days, without pain. Treatment ceased in December, 1886. Uterine measurement gradually came down from eight to six centimètres and a half. Menstruation remains normal at present date, without pain, though there is slight narrowing of the cervical passage. Uterus movable, posterior part somewhat thicker than natural; no excess of sensibility; health good.

CASE III.-Madame S., aged 30, no children, good constitution, menstruated at 17 , at first imperfectly and irregularly. When 20 there was a change, and the llow became copious and mixed with clots. At 22, without known cause, was seized with profuse menorrhagia, which lasted for eighteen months, only short intervals of eight or fifteen days, and those painful. Married when 20; at 28 second menorrhagia, which continued for three months, with same symptoms. At 30 , a third attack, which kept her almost constantly in bed from November, 1885, to April, 1886. This was severely painful, and her health gave way. She lost flesh, had frequent gastralgia and vomiting, and found the ordinary treatment useless. Examination of the uterus gave a measurement of seven centinetres. The whole body was enlarged, considerable hard fibrous deposit on right side; the neck hard and resistant.

From April 8th to July 3rd, 11 positive galvano-cauterisations, 150 to 200 milliampères, five minutes. She bore them easily, and returned home after an hour's repose. After the sixth sitting, on May 19th, menstruation came on without pain, and in less quantity than she had seen for six years. The treatment was continued till July, when feeling herself well and able to do her household work, she gave up attendance. Some extra fatigue in August brought on loss for a few days, but it ceased with rest. Since then she has remained quite well, free from pain and pelvic troubles. She is much stronger and stouter. The sound shows only five centimètres and a half

CASE IV. - Madame T., aged 51, mother of ten children, has passed a life of hard work and good health; had a miscarriage when 30 , and besides her own children, suckled three nurslings; menstruation regular and free up to the age of 49 ; disappearance of menses for twelve months ; when 50 was prostrated by menorrhagia, which con tinued for a year. Had much pain in the right iliac region, lost health and strength, and was obliged to give up all work. Went into the Hôpital Lariboisière, and was under M. Dugué for uterine fibroid came out at end of a month with only trifling diminution of the loss, and was found to have a large interstitial hæmorrhagic fibrome, involving the whole uterus; measurement, eight centimetres and a half

The first positive galvano-cauterisation was made en pleine hemorrhagie. She bore it well, and went home to St. Denis after an hour's rest. From this date (December, 1885, to September, 1886) there were sixteen positive cauterisations, from 100 to 180 milliampères, five minutes each, and two negative cauterisations to open the contracting internal orifice. After the second positive cauterisation hæmorrhage stopped. Then followed leucorrhœea, and occasional menstruation without pain. All uneasiness gradually disappeared, health returned, and very early during the treatment she took up again her occupation as itinerant seller of vegetables. She is now in good health, has no discomfort, and the menses have entirely ceased. The tumour has become much smaller, and the last measurement gave only six centimètres and a half.

The four cases of which I have given a slight outline are specimens of the work which is going on all the year round at the clinique of Dr. Apostoli. There is nothing exceptional in them, and they give an idea of what may be expected from the treatment when applied to the great bulk of hæmorrhagic fibroids oscurring in the course of medical practice. I have carafully gone through the original notes of these cases, verifying most of the statements by the oral accounts of the women, and by their assurances and my own examinations I have satisfied mfself of the benefits they have received. Many others I have watched from day to day, have noted their progress, and am in a position to testify as to the results. My eight months' experience would enable me greatly to multiply the evidence; but as Dr. Apostoli intends to have a paper read beforo the meeting of the Association in Dablin, in which he will give the statistics of his operations from July, 1882, to July, 1887, such a repetition of facts would be superfluous.

There are, however, cases of fibroids in which the use of the galvanocauterisation is not immediately applicable, or is inapplicable in the samo degree. These exceptions are of three kinds; cases in which there is a temporary accession of hysterical excitahility ; cases in which we find what Apostoli calls "entérite glaireuse," and others of a subacute form of perimetritis. These conditions must be overcome before the special treatment is commenced, or, if it be attempted, it must be done with extreme moderation and caution. A very few cases only of absolute intolerance are observed. They are generally women in whom there is a high degree of hysterical susceptibility. Such intolerance may baffle us for a time only if we have patience to study the conditions and modify the way of dealing, though in a few instances neither moral influence nor medical treatment has been able to overcome it.

With a delicacy of tactual perception, a cautious regulation of the operative movements, and a watchful eye upon the indications given by the expression and involuntary actions of the patients, there is no danger in these proceedings. The pain is insignificant, the inconvenience very trifling-so little, in fact, that we often have to put a check upon the impatience which ignorartly calls for more active work than would be safe or useful. The treatment does not interfere with the possibility of subsequent pregnancy, and sometimes it seems to be the means of removing the cause of previous sterility.

\section{ON THE VALUE OF HODGE'S PESSARY.} BY ALEXANDER DUKE, F.K.Q.C.P.I.,

Ex-Assistant Master Rotunda Hospital ; Gynæcolocist Steevens' Hospital, Dublin.

Wirhout at all agreeing with those who think that the primary cause of all female complaints can be traced to uterine misplacement, I still consider that there is a large percentage of such cases to be met with due to that cause; and it is a most furtunate matter that by the judicious use of a Hodge's pessary we are enabled to give more relief in cases of retroflexion and retroversion (the most common forms of uterine misplacement), than by any other means with which I am acquainted.

This pessary is the original from which all the numerous so-called improved uterine supports are taken ; and it will seldom chance that those who fail to give relief with a properly fitted "Hodge" will be fortunate enough to succeed with any of the numerous uterine supports sold by the instrument makers.

Emmet says very forcibly on this point: "I have never known a practitioner who was able to fix this pessary properly who was not fully satisfied with the benefit derived from its use."

The position of the patient during the introduction of the pessary is most important, and the genu-pectoral, affording as it does the favour of gravitation to the uterus, and, in addition, helping greatly to retain that organ in the desired position till a suitable pessary is chosen and placed in situ, should be the position as a rule adopted, unless contra-indicated by some pectoral or cardiac lesion. In no case should a pessary be introduced till the uterus has been replaced as nearly as possible in its normal position.

How of ten is one blindly inserted while the patient lies on the side or back, probably after the uterus has been rudely rotated forwards by the sound (on the withdrawal of which instrument it is almost 
certain that the temporarily replaced organ will return to its abnormal position). or the impaled organ is held firmly forwards while the pessary is forced into place, the handle of the sound being used as a guide. All this can be avoided by adopting the position I recommend and using my uterine repositor, which acts externally to the uterus, and so dispenses with the use of the sound in these cases altogether, except perhaps for the purpose of diagnosis. There are several cases on record where the womb has been perforated by in. judicious attempts to use this instrument, and this danger should be remembered when efforts are being made to remedy a misplacement by its means, as still recommended by some of the latest text-books on the subject. In my opinion, neither the uterine sound, nor any other instrument, however ingenious, introduced into the uterine cavity, should ever be used to remedy a malposition, but should only be used for diagnostic purposes, for which, I believe, the "sound" w2s originally designed.

I have often remarked that in women with broad pelves there is much more tendency to misplacement of the womb, so that the value of this pessary, if only by affording a certain amount of fixity and rest to the organ, is certainly not the least of its many advantages.

I have found it very useful to examine patients in the erect position where symptoms point to flexion or prolapse, as the laxity of the ligaments can be much more easily determined by the mobility of the aterus upwards.

It will also be found useful to direct the patient to bear down during the examination, when, by the patient's voluntary efforts, the uterus can be felt to come down much lower in the vagina, shortening the fornices, and so giving greater facility for diagnosing a flexion or prolapsed ovary. Should the uterus be tender to the touch, it will be advisable not to introduce a pessary, or, indeed, attempt to remedy the displacement till local depletion has been practised or a glycerine tampon introduced and allowed to remain in situ for twenty-four hours, after which the uterus will probably tolerate manipulation.

There are some who maintain that it is quite impossible to cure a chronic misplacement by means of pessaries; for my own part I am convinced that if the rules which I invariably follow myself, were generally adopted, the permanent curability of misplacement by the proper use of this pessary would be universally admitted. The points to which I attach most importance in this connection are: First, the replacing of the uterus in as nearly as possible its normal position by means of the repositor. Secondly, the judicious selection and application of a suitable instrument; and thirdly, the graduated change of pessary at regular intervals.

By substituting a slightly longer instrument at each change of the pessary (till the normal position is retained without the necessity for wearing one any longer), I find, if the last instrument applied has been worn for a sufficient time, there is no return of the misplacement whatever. I am a firm believer in the Hodge's lever action, when properly placed in situ, and this can be put to ocular demonstration by raising the posterior wall of the vagina with the duckbill speculum when, if the patient be in proper position, and the pessary mainly held in place by the lateral pressure of vaginal walls, it will be observed to move backwards and forwards by each inspiration and expiration of the patient. It is this valuable property of the pessary which slowly but surely raises the body of the uterus, and by taking the weight and strain off the ligaments, allows them gradually to regain their natural tone and elasticity, a point almost as important as the reposition of the organ itself.

The periodical change of pessary till the normal position is permanently obtained is to my mind one of the most important points in the treatment, the neglect of which rule has (in some cases at least) caused this valuable instrument to be unjustly condemned.

I have on several occasions heard patients complaining of the presence of a pessary (which, if properly adjusted, should never be the case) and stating they had been assured by the physician who had introduced it, that the pain and discomfort complained of could not passibly be due to that cause ; when on examination the instrument has been found to be at fault, either by being too long or improperly eurved, and so by pressing on the neck of the bladder, or obstructing the circulation in the soft parts, exemplified in a marked degree "the vicious action of the Hodge." "Well may Emmet say, in his well known work, "The practitioner to become an expert in fitting a pessary that may do no harm must have a decided mechanical talent."

Another of the valuable points of advantage in the use of this in. strument is, that even should the misplacement take a considerable time to rectify permanently (which time can be roughly calculated from history of case and date of primary cause), the strain being taken off the uterine ligaments, and in many cases the pelvic nerves as well, it is a pleasure to see the patient, who a short time before limped into the study bowed down with pain, enabled to leave it before long with marked relief to all her symptoms, again erect in posture, and showing, beyond contraversion, the invaluable aid to be rendered by a properly adjusted, well.fitted Hodge's pessary.

\section{ON A CASE OF REMOVAL OF THE ENTIRE UTERUS FOR CANCER AFFECTING THE CERVIX. \\ By EDWARD COTTERELL, M.R.C.S.Eng., L.R.C.P.Lond.}

Extirpation of the uterus may be performed either by Freund's or by Schröeder's method, the latter offering many advantages, amongst which may be mentioned greatly decreased mortality, greater simplicity in its performance, and another notable feature-the whole, or nearly the whole, of the Fallopian tubes may be removed at the same time, and this especially in cases of hysterectomy for cancer, where the body has not hecome greatly involved.

I am aware that it is usually stated that this is not correct, and that one drawback to the vaginal operation is stated to be that the tubes are left bebind, because if they are removed there is not room to apply a secure ligature to the broad ligaments, and secondary hæmorrhage may ensue.

The lesving of the tubes, these being structures in direct continuity with the uterus and its lining membrane, is a fundamental breach of the law which governs all operations for the removal of malignant disease.

In the case I am about to describe, I was able to remove nearly the whole of the right Fallopian tube and the greater part of the left one, and I have no doubt that in operating upon another case I shall be able to remove the whole of both tubes, and thus do away with this most serious objection.

With these preliminary remarks, I will now proceed to describe the case operated upon.

On September 24th, 1886, I was called to see the patient, E. E., aged 48 years. She stated that she was flooding, and had been doing so for some hours. She was perfectly blanched, and had a very feeble pulse. The hæmurrhage was arrested by appropriate means, and the cause was found to be a malignant growth from the cervix uteri.

She had been married twenty-nine years, and had had her first child twenty-six years ago; altogether she had had thirteen children ; the youngest was 9 years old. Her labours inad always been difficult, but had not required instrumental interference; at the first labour there was said to have been an adherent placenta; after the birth of the second child, she was told that she had ulceration of the cervix, which was cauterised. There was no family history of malignant disease.

She had had leucorrhoea more or less since her marriage. She noticed that the vaginal discharge became offensive about June, 1886. Menstruation ceased six years ago.

On October 17 th an anæsthetic was administered. The urine was drawn off with a catheter, and the patient placed in the lithotomy position. A ligature was then put round the large vaginal growth as high up as possible; upon tightening this it cut through the mass, which was removed. The vagina was then syringed out with perchloride solution. A Sim's speculum was introduced into the vagina and a sound into the bladder. A pair of vulsellum forceps were applied to the stump of the uterus, and forcible traction was made. An incision was made in front of the uterus, and the bladder and peritoneum stripped off as high up as possible. A similar incision was made posteriorly, and the peritoneum stripped off behind, and the lateral parts of the cervix were denuded of tissue. The peritoneum was then perforated before and behind, and forcible traction made by drawing down the vulsellum forceps. A pair of Wells's clamp-forceps were fixed on each side of the broad ligament, and the uterus removed by cutting through this structure. The peritoneal cavity was carefully sponged with perchloride solution. There was no hæmorrhage. Iodoform was dusted in, and a large india-rubber drainage-tube inserted into the peritoneal cavity. The vagina was then packed with dry iodoform wool, and the patiunt put to bed.

Upon recovering from the anæsthetic there was little or no shock. The operation was done about 11 A.M. At 6 P.M. the temperature was $100^{\circ} \mathrm{F}$. At 8 A.M. the next morning it was normal. At 7.30 P.M. next day the vaginal packing was removed, and Wells's forceps taken away. The bowels were opened by an injection on the fifth day. On the thirteenth day the patient sat out of bed for two hours, and from this time convalescence became rapidly established.

Subsequent History. - About three months after the extirpation of the uterus it was noticed that the vaginal walls, which at the time of the operation were apparently free from disease, had become infiltrated with a recurrence of the growth. The patient died seven months after the operation. 